\title{
A participação dos animais na fraternidade em Cristo
}

\section{Animals participation in the fraternity in Christ}

\author{
Afonso Tadeu Murad* \\ Marco Túlio Brandão Sampaio Procópio**
}

Recebido: 30/08/2017. Aprovado: 23/11/2017.

Resumo: O mistério da encarnação e da ressurreição tem repercussão não somente para a humanidade, mas para todas as criaturas. Há uma fraternidade cósmica que encontra respaldo não somente no relato da criação, mas também no mistério de Cristo. Particularmente os animais são colocados como verdadeiros irmãos e irmãs dos seres humanos por uma apropriada leitura teológica e hermenêutica bíblica. Entretanto, essa relação fraternal proposta pela tradição cristã depara-se com sua antítese expressa na atual relação de exploração animal. Os animais são hoje vítimas de um ciclo de sofrimento no mais alto grau, submetidos à escravidão, tortura e morte. A vontade de Deus expressa na Bíblia e em Cristo, porém, não é essa, mas de paz e justiça entre suas criaturas. Este trabalho apresenta a perspectiva cristã da relação entre os seres humanos e os animais, contrastando com a realidade atual e propondo caminhos de ação.

Palavras-chave: Fraternidade cósmica. Teologia animal. Exploração animal. Ecoteologia.

Abstract: The mystery of incarnation and resurrection has repercussions not only for humanity, but for all creatures. There is a cosmic fraternity that finds support not only in the account of creation, but also in the mystery of Christ. Particularly the animals are placed as true brothers and sisters of human beings by an appropriate theological reading and biblical hermeneutics. However, this fraternal relationship proposed by the Christian tradition is confronted with its antithesis expressed in the current relationship of animal exploitation. Animals today are

* Doutor em Teologia (Pontifícia Universidade Gregoriana, Roma, 1992). Professor na Faculdade Jesuíta de Filosofia e Teologia (FAJE) e no Instituto Santo Tomás de Aquino (ISTA), ambos em Belo Horizonte. Pesquisador em Ecoteologia. Orientador deste artigo.

E-mail: amurad@marista.edu.br

** Mestrando em Teologia pela Faculdade Jesuíta de Filosofia e Teologia (FAJE). Graduado em Ciências da Religião (Universidade Estadual de Montes Claros, MG (Unimontes), 2014). Bolsista da Capes.

E-mail: mtbsp88@yahoo.com.br 
victims of a cycle of suffering in the highest degree, subjected to slavery, torture and death. The will of God expressed in the Bible and in Christ, however, is not that, but peace and justice among his creatures. This work presents the Christian perspective on the relationship between human beings and animals, contrasting with current reality and proposing paths of action.

Keywords: Cosmic fraternity. Animal theology. Animal exploitation. Ecotheology.

\section{Introdução}

A teologia cristã foi marcada por uma perspectiva predominantemente antropocêntrica, negligenciando a relevância das outras criaturas para o projeto salvífico de Deus. Nessa linha também a cristologia tem refletido pouco acerca de sua dimensão cósmica, e apenas minimamente tem-se discutido sobre as repercussões, implicações e desdobramentos do mistério de Cristo para a Criação.

A encarnação e a ressurreição abarcam não somente toda a humanidade, mas também todo o cosmos, pois todas as coisas foram criadas

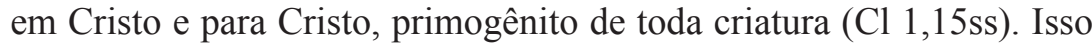
sugere uma ontológica fraternidade entre tudo o que existe. Os animais, entretanto, formam biblicamente laços relacionais ainda mais próximos com os seres humanos, e participam com estes de uma especial condição moral. Ambos possuem a capacidade de sentir dor e prazer, e devem ser respeitados nessa particularidade. Essa, porém, não é a realidade contemporânea.

Atualmente há um genocídio sistemático e estrutural que tem lugar em indústrias construídas com este objetivo: explorar lucrativamente os animais, tomados como coisas. Sua capacidade de sentir dor e prazer e seus interesses de vida e liberdade são completamente ignorados em detrimento da demanda do consumidor em uma relação parasitária. São utilizados para diversos fins, como alimentação, produção de cosméticos, pesquisa científica, entretenimento, transporte, fabricação de casacos de peles, proteção de propriedades etc.

Uma leitura teológica advinda de uma hermenêutica bíblica apropriada aponta para outra direção. Indica-nos o caminho do cuidado e do serviço, seguindo o exímio exemplo de Cristo, bom pastor que dá a vida por suas ovelhas (Jo 10,11). Somente nessa linha a relação entre seres humanos e animais é biblicamente aceitável. Deve-se cuidar da Criação de modo similar à forma como Deus mesmo cuidaria, e principalmente seguindo o modelo de Cristo, o mais perfeito exemplo moral a seguir. 


\section{O mistério da encarnação}

Tradicionalmente a encarnação tem sido pensada e refletida teologicamente apenas em termos antropocêntricos. Pouco se discute acerca das repercussões desse mistério para toda a Criação. O ponto central tem sido repetir que o ato de se fazer humano traduz concretamente um verdadeiro amor de Deus pela humanidade. Entretanto, pode-se propor uma abordagem mais ampla. Não somente Deus se faz homem, mas faz-se antes criatura, e, em ato de absoluta liberdade e amor, vai ao seu encontro daquilo que Ele próprio criou.

Andrew Linzey ${ }^{1}$ defende que a encarnação deve ser vista em perspectiva cósmica, com significância para a inteira Criação, e não exclusivamente para a humanidade. Esse teólogo anglicano, que ocupa o primeiro posto acadêmico do mundo em Ética, Teologia e Bem-estar Animal, acusa a Teologia da Libertação de ser excessivamente humanocêntrica, e, portanto, exclusivista. Ela negligencia os outros seres vivos do plano moral, apesar de seus importantes avanços. Dentre as autocríticas necessárias, segundo os apontamentos do teólogo, está precisamente a compreensão do mistério da encarnação. Ele assume que, mais do que fazer-se humano, Deus se fez carne, assumindo assim toda a realidade material e dando um "sim" a todos os seres vivos, e não somente à humanidade².

Pode-se ensaiar uma hipótese de que existe uma sequencialidade no mistério da encarnação, não cronológica, mas ontológica. Para se ser uma coisa, é necessário antes ser outra, ainda que sejam cronologicamene simultâneos. Para fazer-se humano, é necessário ontologicamente antes ser vida, e anteriormente ainda ser matéria, pois uma coisa não se dá sem a outra. Seguindo essa linha, pode-se assumir que a condição do existir humano acontece em três etapas simultâneas, numa sequencialidade não temporal ou cronológica, mas ontológica: primeiro sendo matéria (corpo), depois sendo vivo (corpo animado), e assim fazendo-se humano (corpo animado na condição de existir propriamente humana).

Essa sequencialidade ontológica manifestou-se cronologicamente no processo evolutivo cósmico: primeiro surge a matéria, com a explosão do Big Bang, depois, com a complexificação da própria matéria, nasce a

LINZEY, Andrew. Creatures of the same God: explorations in animal theology. New York: Lantern Books, 2009. p. 14

2 LINZEY, Andrew. Los animales en la teologia. Tradução de Ignacio Ribera Galán. Barcelona: Herder, 1996. Título original: Animal theology. p. 117-118. 
vida, e, só em um último momento, emerge o ser humano. Essa realidade se expressa na frase retomada por Leonardo Boff: "O Espírito dorme na pedra, sonha na flor, acorda no animal e sabe que está acordado no ser humano"s.

Da mesma forma, Deus, em processo ontológico (não cronológico), para se fazer humano, fez-se antes vida, e ainda anteriormente, matéria. O mistério da encarnação é, portanto, um imenso abraço mistérico que tudo acolhe em seu seio, que engloba as coisas visíveis e invisíveis, que abarca tudo o que existe em todas as suas dimensões, do mais ínfimo ao mais grandioso. À semelhança da analogia utilizada por Jesus da galinha que acolhe os pintinhos sob suas asas (Mt 23,37), a encarnação é o acolhimento de toda a Criação nos braços de Deus encarnado.

A "descida" de Deus ao mundo criado ressoa, portanto, nas mais elementares partículas materiais, porque Ele mesmo se fez matéria. Seu mistério percorre desde as partículas da pedra, passando pelo homem e pela mulher, até as mais grandiosas estrelas e galáxias nos recônditos confins do Universo. Assim, Deus encarnado tem significância para toda a Criação, redimindo ela toda também.

Mas é insuficiente afirmar sua significância cósmica. Deve-se também questionar quais as implicações práticas dessa realidade. Integrando-se no mundo das criaturas, esvaziando-se a si mesmo (kenosis), Jesus encarna a perfeição das potencialidades humanas e faz-se modelo moral, convidando-nos ao seguimento. Mas só o faz a partir da sua assumida condição material, vital e humana em todas as suas particularidades, dentre as quais, a realidade do sofrimento. "Certamente, a dor representa um dos aspectos do sofrimento da criação e, assumindo o sofrimento, o Cristo toca num ponto sensível dos seres vivos, pois essa

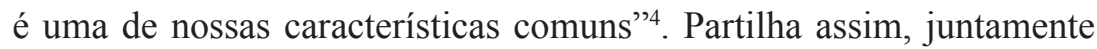
aos seres sencientes, da capacidade de sentir dor. E não somente assim o faz, como assume especialmente a dor dos mais pequeninos (Mt 25,40). Desse modo, Cristo sofre e padece no sofrimento e padecimento de toda a Criação e de cada criatura, cada uma em sua especificidade ontológi-

3 BOFF, Leonardo. De Onde Vem?: uma nova visão do universo, da Terra, da vida, e do ser humano. llustrado por Adriana Miranda. Rio de Janeiro: Mar de Ideias Navegação Cultural, 2016. p. 73.

4 PALHANO, Jerson José Darif; SANCHES, Mario Antonio. Teologia da compaixão com os animais: a prática de Jesus. Revista Pistis Praxis, Teol. Pastor., Curitiba, v. 5, n. 1, p. 169-184, jan./jun. 2013. p. 180. 
ca. Tudo então deve ser respeitado nas respectivas capacidades de sua particular condição de existir.

\section{Cristo Cósmico e Jesus Ressuscitado}

Leonardo Boff $f^{5}$ assinala a presença de uma vertente mística no Novo Testamento que afirma a presença tanto do Filho quanto do Espírito na Criação, que aí estão "fermentando o processo de ascensão rumo ao Reino da Trindade". Essa convicção trouxe a experiência do Cristo Cósmico já aos primeiros cristãos, e pode-se citar Santo Atanásio como um exemplo patrístico. Ele afirmava que o Logos, a tudo iluminando e a tudo contendo em si, dando vida a cada criatura particularmente e a todas juntas, cria uma única e harmoniosa melodia no conjunto da Criação ${ }^{6}$.

Há passagens bíblicas que afirmam claramente a presença de Cristo em todos os seres, e que sugerem mesmo uma fraternidade crística com a Criação. São Paulo escreve que "Ele é a Imagem do Deus invisível, $o$ Primogenito de toda criatura, porque nele foram criadas todas as coisas [...] tudo foi criado por ele e para ele. É antes de tudo e tudo nele subsiste" (Cl 1,15ss). Não se relaciona Cristo à humanidade, exclusivamente, mas com todas as criaturas, sem nenhuma exceção. Tudo está incluído. Boff $^{7}$ destaca uma série de outros textos neotestamentários que seguem a mesma linha, como Jo 1,3; Hb 1,2; Ef 1,3-14; Ap 1,8;21,6.

A experiência do Cristo Cósmico, por sua vez, aponta para a presença do Ressuscitado na Criação. O Papa Francisco, na Encíclica Laudato $\mathrm{Si}^{\prime}{ }^{8}$, lembra-nos que o Novo Testamento fala tanto da experiência terrena de Jesus, na qual se encontra plenamente imerso na Criação por laços de amor e carinho, quanto do Cristo ressuscitado, que tudo envolve e encaminha todas as coisas para a plenitude do amor de Deus. Ele afirma que "o destino da criação inteira passa pelo mistério de Cristo, que nela está presente desde a origem" (LS 99).

5 BOFF, Leonardo. Ecologia, Mundialização, Espiritualidade: A emergência de um novo paradigma. São Paulo: Ática, 1993. p. 151.

6 LINZEY, 2009, p. 14

7 BOFF, Leonardo. Ecologia: grito da Terra, grito dos pobres: dignidade e direitos da Mãe Terra. Petrópolis,: Vozes, 2015. p. 370.

8 PAPA FRANCISCO. Carta Encíclica Laudato Si'- Sobre o Cuidado da Casa Comum. São Paulo: Loyola, 2015. 
Assim, as criaturas deste mundo já não nos aparecem como uma realidade meramente natural, porque o Ressuscitado as envolve misteriosamente e guia para um destino de plenitude. As próprias flores do campo e as aves que Ele, admirado, contemplou com os seus olhos humanos, agora estão cheias da sua presença luminosa (LS 100).

A dimensão crística da realidade oferece elementos para uma espiritualidade de verdadeira integração, onde se pode encontrar a presença do Ressuscitado na sacralidade da matéria, contemplar Sua beleza na beleza da Criação, sentir Sua dor na dor de Suas criaturas. Essa espiritualidade permitiu que místicos identificassem o sofrimento de Cristo no sofrimento de criaturas tanto humanas quanto não humanas, percebendo os laços que nos unem a todos.

Vários misticos cristãos se referem ao Deus que sofre com os que sofrem e que chora por aqueles que morrem. Juliana de Norwich (1342-1416), grande mística inglesa, viu a conexão existente entre a paixão de Cristo e a paixão do mundo. Numa de suas visões, diz: 'Então vi que, no meu entender, era uma grande união entre Cristo e nós; pois, quando ele padecia, padecíamos também. E todas as criaturas que podiam sofrer sofriam com ele'. William Bowling, outro místico do século XVII, concretizava ainda mais, dizendo: 'Cristo verteu seu sangue tanto pelas vacas e pelos cavalos quanto por nós homens'. É a dimensão transpessoal e cósmica da redenção9.

Permeados então pela luminosa presença crística, podemos identificar e sentir a mística fraternidade e sororidade de todos os seres e de todas as criaturas, todas partícipes da mesma condição em Cristo, igualmente imersos em Seu amor. Há, assim, em Cristo, uma mesma família cósmica, onde todos, da menor e mais simples à maior e mais complexa criatura, fazem-se fundamentalmente irmãos e irmãs.

\section{Uma mesma fraternidade entre seres humanos e animais}

A partir dessas reflexões, uma questão emerge com relevantes desdobramentos morais: se toda a Criação é amada por Deus, não há diferença entre humanos, animais e plantas? Pode-se dizer que dentro

9 BOFF, Leonardo. Cuidar da Terra, proteger a vida: como evitar o fim do mundo. Rio de Janeiro: Record, 2010. p. 298. 
da imensa família cósmica existem criaturas que se colocam diante de nós com uma proximidade existencial maior, que são os animais não humanos, "pois a sorte do homem e do animal é idêntica: morre um, as-

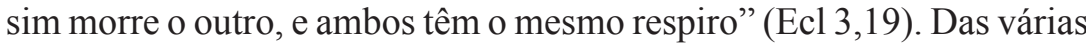
características que partilham conosco, pode-se destacar a senciência, que é a capacidade de sentir dor e prazer.

Linzey aponta como essa proximidade tem respaldo bíblico, delineando uma comum-unidade entre seres humanos e animais. Ele diz que o versículo "Salvas os homens e os animais, Senhor" (S1 36,6) é um fio condutor que perpassa toda a Bíblia. Nesta, o Espírito é o "sopro da vida" tanto em humanos quanto em animais (Gn 1,30) ${ }^{10}$ (LINZEY, 2000, p. 38-41). Ambos são colocados lado a lado no relato da Criação no sexto dia ${ }^{11}$ (Gn 1,24-31). São abençoados com a mesma bênção (Gn 1,22.28), e também são conjuntamente amaldiçoados (Jr 7,20). A Torá inclui tanto seres humanos quanto animais dentro da comunidade moral, de modo que a santificação do sábado é dada pelo descanso tanto de uns quanto de outros (Ex 20,8-11; Ex 23,12). Existem até mesmo leis que conferem obrigações dos seres humanos com os animais (cf. Ex 23,4-5; Dt 25,4). Desse modo, pode-se perceber que "animais não humanos e humanos são indissociáveis diante de Deus. Por isso, em Gênesis 8,1, o autor escreve que 'Deus lembrou-se de Noé, de todos os animais e de todo o gado que estavam com ele na arca""12.

A proximidade entre seres humanos e animais pode ser chave de leitura para diversas passagens bíblicas. Exemplos disso são a definição de próximo na parábola do bom samaritano (Lc 10,36-37), a identificação de Jesus com o menor como orientação de práxis moral (Mt 25,40), e a metáfora joanina de Jesus como o bom pastor, aquele que dá a vida por suas ovelhas (Jo 10,11).

A comunidade de seres humanos e animais carrega importantes repercussões éticas, e essa união é tão evidente que amar a um e maltratar a outro, mais do que uma incoerência, é uma impossibilidade.

10 LINZEY, Andrew. Animal Gospel. Louisville, Kentucky: Westminster John Knox Press, 2000. p. 30-36.

11 Com exceção das aves e animais marinhos, criados no quinto dia ( $G n$ 1,20-23).

12 PALHANO, Jerson José Darif; SANCHES, Mario Antonio. Sobre os animais não humanos: um resgate teológico. Revista BioEthikos, São Paulo, v. 6, n. 3, p. 287-299, jul/set 2012. p. 296. 
[...] a indiferença ou a crueldade com as outras criaturas deste mundo sempre acabam de alguma forma por repercutir-se no tratamento que reservamos aos outros seres humanos. O coração é um só, e a própria miséria que leva a maltratar um animal não tarda a manifestar-se na relação com as outras pessoas (LS 92).

Dessa forma, a violência perpetrada contra os animais torna-se também violência cometida contra seres humanos, e vice-versa. $\mathrm{O}$ amor é universal, e a esfera da práxis moral deve portanto englobar tudo, principalmente seres humanos e animais, unidos em seu sofrimento, ambos capazes de sentir dor e prazer. O escritor russo Tolstoi bem expressou essa íntima interligação ao afirmar, em seu livro $V$ chem moia viera? ${ }^{13}$, de 1884, que "enquanto existirem abatedouros, existirão campos de batalha". Enquanto se perpetua o ciclo de violência imposta pelos seres humanos contra os animais, aqueles continuarão se digladiando uns contra os outros.

\section{A relação atual}

Um genocídio sistemático contra os animais ocorre nas sociedades atuais, sustentado pela maior parte de nós. A escravidão, a tortura e a morte tornou-se um ciclo de sofrimento que é imposto aos nossos irmãos menores em Cristo. Apesar de ter legalidade jurídica, interpela-nos como um absurdo moral. Para diversos fins os animais são utilizados pelos seres humanos como se fossem coisas ou objetos inertes, como se não tivessem qualquer sensibilidade à dor ou quaisquer interesses na vida, na liberdade, na felicidade. Apesar de repetidas vezes o Papa Francisco alertar-nos sobre o valor intrínseco de cada criatura ${ }^{14}$, independentemente do valor que lhes atribuímos, eles continuam a ser tratados como instrumentos ou mercadorias na sociedade de consumo.

A fim de organizar melhor as diversas facetas da exploração animal, utilizaremos a divisão proposta por Luis Carlos Susin e Gilmar Zampieri ${ }^{15}$, inspiradas na analogia do escritor J. M. Coetzee em seu livro "A vida dos animais". Os autores falam de 5 campos de concentração

13 "Qual é a minha fé?", em tradução livre, e publicado em inglês com o título "What I believe", em 1885.

14 LS 33, 36, 42, 68, 69, 76, 77, 82, 118, 140, 208.

15 SUSIN, Luiz Carlos; ZAMPIERI, Gilmar. A vida dos outros: ética e teologia da libertação animal. São Paulo: Paulinas, 2015. p. 27-65. 
animal, que serão relatados a seguir. Em todos eles perpassa a mentalidade e o tratamento dos animais como coisas ou recursos, e não como seres vivos com valor próprio ${ }^{16}$.

Do primeiro campo de concentração ${ }^{17}$, animais de estimação, pode-se dizer que é o mais brando, e que existem pessoas com real interesse na vida plena do animal. Porém há também a exposição de cachorros, gatos, hamsters, coelhos e outros em vitrines de petshop, "etiquetados" com um preço. Eles podem ser levados para casa mediante o simples pagamento desse valor, como se fossem mercadorias, de forma que se reforça o pensamento dos animais como coisas. Muitas vezes são abandonados por razões fúteis ou sofrem de maus-tratos, e em outros casos sofrem meramente por uma incompreensão de seus "donos", que cortam as orelhas ou o rabo a fim de parecerem esteticamente mais bonitos.

No segundo campo de concentração estão os animais para entretenimento ${ }^{18}$. Muitos animais são raptados de seu habitat natural ou deixam de ser lá reintroduzidos a fim de serem expostos como produtos exóticos em espaços inadequados de zoológicos. Em circos, leões e tigres são ensinados a saltar por argolas, ursos a pedalar bicicletas, elefantes a fazerem acrobacias, entre outras atividades totalmente alheias a suas condições naturais de existência. Em rodeios, bois são montados após terem uma cinta apertando seu abdômen e virilha, e bezerros são cruelmente laçados. Há também as rinhas de cachorros e galos, a corrida de galgos e cavalos, entre outras categorias que têm a intenção de provocar entretenimento mediante a dor de outras criaturas. Em todas essas atividades citadas há uma enorme carga de sofrimento, estresse e tortura dos animais escravizados para tal fim, e muitas vezes o resultado final delas é uma morte bastante dolorosa.

O terceiro campo de concentração consiste em animais como instrumento de pesquisa ${ }^{19}$. Diversos animais são submetidos a cruéis experimentos para se realizar testes para a fabricação de cosméticos ou para produção de medicamentos. A validade e legitimidade da pesquisa que utiliza animais em testes é amplamente questionada, pois muitas drogas consideradas seguras após testes em animais mostram-se danosas

\footnotetext{
16 Um melhor contato com a realidade animal na relação com os seres humanos pode ser vislumbrado no lúcido documentário Terráqueos (2005), do diretor Shaun Monson.

17 SUSIN e ZAMPIERI, 2015, p. 28-31.

18 SUSIN e ZAMPIERI, 2015, p. 31-37.

19 SUSIN e ZAMPIERI, 2015, p. 37-42.
} 
quando aplicada em humanos ${ }^{20}$, e já existem muitas alternativas viáveis para a questão ${ }^{21}$. Neste campo se encontram macacos, gatos, ratos, rãs, coelhos, porcos, cavalos, cachorros, pombos e peixes. Apenas como exemplo do sofrimento infligido, pode-se citar o teste Draize, que "consiste em avaliar alterações oculares e perioculares provocadas pelos mais variados produtos químicos"22. Ele é utilizado desde 1944, e é realizado geralmente em coelhos albinos, por terem olhos grandes e serem dóceis.

Nos olhos do coelho, com as pálpebras presas com grampos para que os olhos fiquem permanentemente abertos, sem anestesia, são adicionadas doses de substâncias quimicas, por dias e dias sem parar, até que os olhos se transformem em uma massa irritadiça e dolorida. Outra modalidade do teste Draize consiste em raspar a pelo do animal até o sangramento, aplicando, então, a substância a ser estudada para observar a sensibilidade e irritabilidade cutânea ${ }^{23}$.

Estima-se que sejam entre 200 milhões a 500 milhões o número de animais mortos a cada ano em laboratórios de experimentação ao redor do mundo ${ }^{24}$. E além disso, muitos outros animais são utilizados ainda com fins educacionais em escolas e universidades. São abertos nas práticas de dissecção ou de vivissecção em aulas de anatomia e fisiologia, mesmo já existindo também diversas alternativas viáveis para as mesmas finalidades.

No quarto campo de concentração estão os animais como utensí$\operatorname{lio}^{25}$. Muitos seres vivos são tratados como insumos para a produção de materiais apreciados pelo público consumidor. São criados com o fim de serem assassinados e terem seus corpos ou parte dele servindo como matéria-prima para a produção de uma peça. "Neste campo o animal vira sapato, chinelo, casaco, bola, cinto, almofada, sofá etc." ${ }^{26}$. Fazem

20 "Somente entre 1968 e 1993, pelo menos 124 remédios foram tirados do mercado após terem se mostrado prejudiciais a humanos, embora tenham antes obtido o certificado público de segurança depois de testes intensivos em animais" (HORTA, 2015, p. 52).

21 Exemplo de discussão nessa linha é o livro Ética e Experimentação Animal (2014), da autora Sônia T. Felipe.

22 SUSIN e ZAMPIERI, 2015, p. 41.

23 SUSIN e ZAMPIERI, 2015, p. 41.

24 HORTA, Reginaldo José. Por uma ética não especista: Peter Singer e a questão do estatuto moral dos animais não-humanos. Dissertação de mestrado. Faculdade Jesuíta de Filosofia e Teologia (FAJE), Belo Horizonte: 2015. p. 49.

25 SUSIN e ZAMPIERI, 2015, p. 42-47.

26 SUSIN e ZAMPIERI, 2015, p. 42. 
parte da chamada indústria de pele linces, raposas, guaxinins, chinchilas e minks. $\mathrm{Na}$ indústria da lã fazem parte os carneiros. E da indústria do couro sofrem vacas, bois, touros, porcos, cabras, cobras, zebras, bisões, cangurus e diversas outras criaturas.

Por fim, o quinto e último campo de concentração é o de animais utilizados para alimentação ${ }^{27}$, e consiste no maior e mais extenso de todos. Aqui o sofrimento alcança sua pior expressão e a interpelação ética nos atinge em alto grau. Porcos, vacas, galinhas, peixes, patos, gansos, bezerros, pintinhos e diversos outros animais vivem uma vida miserável de imensa dor e são assassinados depois de um curto período de existência.

É nesse campo que o problema toma proporções de holocausto em massa. Estima-se que anualmente 60 bilhões de animais são criados e sacrificados para alimentação, sem contar os peixes. Isso significa 160 milhões de mortes por dia, 6 milhões por hora e 100 mil por minuto. Os números impressionam e carregam um enorme peso moral, mas não é apenas a quantidade que está em jogo. Imagine em que condições esses animais são criados, transportados e abatidos! Mortos prematuramente, criados com hora marcada para morrer, muitos ainda filhotes. Na indústria da carne, uma galinha, que pode durar até 7 anos em condições naturais, é morta aos 40 dias de vida; um porco, que pode viver até 12 anos, é morto aos 4 meses; um boi, que pode ter uma vida natural de 24 anos, morre com porte de adulto aos 2 anos de idade $e^{28}$.

Esses absurdos morais só são aceitos pela sociedade porque há diversos mecanismos sutis de disfarce, a começar por se manter às escondidas todo o processo de criação e morte dos animais. É de alto interesse da indústria animal que aquilo que se passa dentro dos abatedouros não chegue aos olhos do público, pois as cenas logo lhe causariam extrema indignação. Susin e Zampieri ${ }^{29}$ lembram que tentativas similares aconteciam nos campos de concentração nazista, pois não se poderia justificar à população aquilo que é simplesmente injustificável. "Existe uma direta e fundamental correlação entre a visão e a sensibilidade. $\mathrm{O}$ que nós não podemos ver, nós não podemos significativamente apropriar

27 SUSIN e ZAMPIERI, 2015, p. 47-65.

28

ZAMPIERI, Gilmar. A Encíclica Laudato Si' e os animais. Cadernos Teologia Pública, ano XII, v. 13, n. 110, São Leopoldo: Universidade do Vale do Rio dos Sinos. 2016. p. 8-9. 
por nós mesmos" ${ }^{\prime 30}$. É crucial, portanto, que sejam vistos os crimes que até então estão escondidos.

Além disso, busca-se dissociar pela linguagem aquilo que é vendido daquilo que realmente é. Ou seja, ao invés de se falar pedaço de um boi, fala-se bife ou picanha; no lugar de porco, diz-se costela ou pernil; no lugar de bezerro, fala-se vitela. Semelhante artifício encontra-se nos rótulos de embalagens que escondem a exploração animal. Elas trazem imagens de animais felizes, enquanto seu interior está repleto de sangue.

\section{A relação ideal}

Toda questão moral que interpela o cristão pode encontrar sua resposta definitiva no exemplo de Jesus. Antes disso, porém, convém retornar a Gênesis, onde foi dado ao ser humano domínio e poder sobre toda a Criação. Veremos mais adiante como as duas questões estão intimamente interligadas.

Linzey $^{31}$ aponta como no primeiro capítulo de Gênesis, logo ao lado da afirmação do ser humano como imagem e semelhança de Deus (v. 26) e da Criação dada para ele como domínio (v. 28), é lhe prescrito uma dieta vegetariana (v. 29). Esses conceitos estão todos relacionados. Um domínio associado à dieta vegetariana não pode ser compreendido como tirania, e o sentido de poder e governança só pode ser entendido em um sentido secundário, pois o governo primeiro é de Deus. A Ele pertence todas as criaturas ${ }^{32}$, e o ser humano é convidado a ser vice-regente ou representante de Seu amor na Criação, cuidando desta como Ele mesmo cuidaria $^{33}$. Assim, só se pode devidamente captar o significado de domínio em relação à atitude do próprio Criador no tocante à sua Criação.

O conceito de imagem e semelhança, similarmente, pode ser compreendido no sentido de bem governar, fazendo-o à semelhança do Criador e cumprindo a Sua vontade. "A interpretação bíblica não está pensando ontológica ou metafisicamente, mas em uma vocação, uma missão junto às demais criaturas" ${ }^{34}$. Desse modo, pode-se dizer que os

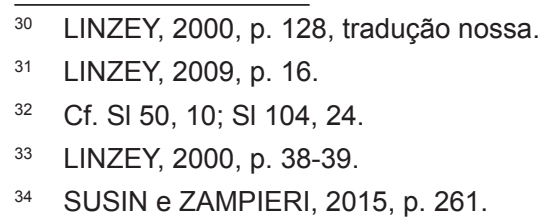


cristãos têm interpretado de forma correta que Deus deu poder aos seres humanos sobre os animais e a Criação, mas não a forma como esse poder é exercido. A única forma legítima de domínio é se ele for exercido da mesma forma que Deus o exerce, expresso em Jesus Cristo ${ }^{35}$.

O Evangelho de João narra que Jesus se reconhece como Senhor e Mestre, mas se abaixa aos pés de seus discípulos e lhes lava os pés (Jo 13,1-15). Esse ato, repleto da mais profunda riqueza simbólica, pode ser posto em analogia ao mistério da encarnação, quando Deus, em toda a Sua infinitude, faz-se finito e do tamanho de Sua criatura ${ }^{36}$. Trata-se de "um Deus que se revela não pelo domínio, mas pelo abrir mão de suas prerrogativas e pela vinda humilde em direção à sua criação para ali revelar-se, fazer morada, conhecer e ser conhecido" ${ }^{37}$.

É nessa linha que pode ser encontrado um apropriado sentido para o exercício do poder, tendo Jesus como referência máxima enquanto autorrevelação de Deus. O poder em Jesus é expresso em impotência, humildade, cuidado, autossacrifício e serviço. Ele orienta explicitamente aos seus discípulos que quem quiser ser o primeiro que seja o último e servo de todos (Mc 9,35). Ele próprio encarna em sua prática a perfeição de seus ensinamentos. Cura os doentes, alimenta os famintos, liberta os oprimidos, e traça um percurso biográfico de amor sacrificial, fazendo completa autodoação de sua própria vida ${ }^{38}$. Em resumo, o poder exercido por Cristo, ao qual devemos plenamente imitar e nos inspirar, significa serviço ${ }^{39}$.

Diante dessas reflexões, verifica-se a necessidade de uma urgente mudança na relação dos seres humanos com os animais. Oposto ao cuidado, a atual situação dessa relação é de domínio em sentido deturpado. Existe, porém, saída para essa crise moral, a começar pelas mudanças individuais. "Há de se fazer uma verdadeira conversão animal, tanto teórica quanto de coração e prática" ${ }^{40}$.

35 LINZEY, Andrew. Christianity and the rights of animals. Eugene: Wipf and Stock, 2016. p. 28-29. 
Individualmente cada um é capaz de se abster de consumir produtos que implicam em exploração animal, e assim, romper com o ciclo de sofrimento. Citando Bento XVI, Papa Francisco nos lembra que "comprar é sempre um ato moral, para além de econômico" (LS 206). Assim, em nossas decisões cotidianas enquanto consumidores somos responsáveis por perpetuar a miséria animal em seu ciclo de escravidão, tortura e morte, ou inaugurar uma nova relação com eles. Podemos optar por consumir produtos que fazem violência a eles, ou produtos que não os exploram. Além disso, em várias esferas de decisão somos interpelados por essa questão, pois, como denunciado anteriormente, a instrumentalização dos animais tem diversas facetas. Nessa linha pode-se citar o veganismo como uma alternativa viável para superar o sofrimento animal.

Sucintamente, o veganismo é uma proposta de conduta ética que prega a libertação dos animais não-humanos por meio da abolição de todas as formas de exploração que lhes são impostas por nós. Na dieta vegana estão excluidos todos os ingredientes de origem animal, como ovos, laticínios e mel (e qualquer tipo de carne, evidentemente), além de itens que contenham ingredientes de origem animal. Quanto ao vestuário, não se utiliza couro (ou qualquer outro tipo de pele), lã ou seda e, no geral, quaisquer produtos ou itens que tenham sido testados em animais, ou que contenham ingredientes de origem animal (por exemplo, cosméticos, produtos de limpeza, aditivos de alimentos, objetos de decoração etc.). O princípio abolicionista, norteador do veganismo, exclui também o comércio de animais de estimação, o uso de animais para esportes ou diversão, a vivissecção, etc. ${ }^{41}$.

Junto com a "conversão animal" a ser realizada individualmente, diversas outras ações contribuem para promover o fim do sofrimento animal. Linzey ${ }^{42}$ propõe vários outros passos: trazer às vistas do público os processos de exploração animal, colocar a respectiva questão ética na agenda intelectual com a contribuição de várias ciências, exigir informação das empresas acerca do processo de produção de seus produtos, avançar juridicamente na legislação em prol dos animais, e promover no mercado opções de alta qualidade livres de exploração animal.

Sonhando com uma Igreja profética na questão animal, o autor propõe também passos na teologia cristã. Primeiro, resgatar passagens bíblicas favoráveis aos animais. Segundo, promover uma verdadeira

41 BRÜGGER, Paula. Nós e os outros animais: especismo, veganismo e educação ambiental. Linhas Críticas, Brasília, v. 15, p. 197-214, jul/dez 2009. p. 13.

42 LINZEY, 2000, p. 126-139. 
teologia animal através de uma metódica e sistemática reflexão acerca da relevância dos animais no plano salvífico de Deus. Terceiro, construir um ministério animal, defendendo a formação da consciência de que é um dever prático cristão se importar com os animais, caminhando na esteira de Jesus que infindamente se preocupa com os mais fracos e vulneráveis. Por fim, incorporar na liturgia ritos e orações que considerem a reverência pela vida e por toda a Criação ${ }^{43}$.

\section{Conclusões}

O mistério de Cristo atinge toda a Criação, e não somente a humanidade, e há uma significância cósmica na Encarnação e na Ressurreição. Todas as criaturas fazem-se, portanto, irmãos e irmãs em Cristo. Os animais, entretanto, estabelecem uma relação com os seres humanos ainda mais próxima, que encontra respaldo tanto em sua condição existencial quanto nos relatos bíblicos. Ambos têm a capacidade de senciência e em ambos o Espírito é o sopro da vida. Essa relação exige, por sua vez, uma especial consideração moral.

Apesar disso, a atual relação dos seres humanos com os animais se encontra na contracorrente do movimento de Jesus e da vontade divina refletida pela teologia cristã, e é perpetrada pela maior parte de nossas ações diárias. Diante dessa realidade o exemplo de Cristo nos interpela a cuidar dos mais fracos e dos mais vulneráveis, a entender poder como serviço, e a fazer de si, enquanto discípulo, modelo de amor sacrificial. Assim, no trato com os animais na sociedade atual, seguir Cristo significa romper com o ciclo de sofrimento, recusar a tomar parte dessa injustiça, e adentrar na esfera do cuidado e do serviço, pondo-se em prol da luta pelo fim do sofrimento animal.

\section{Referências}

BINGEMER, Maria Clara. Teologia e Espiritualidade. Uma leitura teológico-espiritual a partir da realidade do movimento ecológico e feminista. Cadernos Teologia Pública, ano 1, n. 2. São Leopoldo, RS: Universidade do Vale do Rio dos Sinos, 2004.

$\overline{43}$ LINZEY, 2009, p. 98-106. 
BRÜGGER, Paula. Nós e os outros animais: especismo, veganismo e educação ambiental. Linhas Críticas, Brasília, v. 15, p. 197-214, jul./dez. 2009. BOFF, Leonardo. Ecologia, Mundialização, Espiritualidade: A emergência de um novo paradigma. São Paulo: Editora Ática, 1993.

. Cuidar da Terra, proteger a vida: como evitar o fim do mundo. Rio de Janeiro: Record, 2010.

. Ecologia: grito da Terra, grito dos pobres: dignidade e direitos da Mãe Terra. Petrópolis, RJ: Vozes, 2015.

. De Onde Vem?: uma nova visão do universo, da Terra, da vida, e do ser humano. Ilustrado por Adriana Miranda. Rio de Janeiro: Mar de Ideias Navegação Cultural, 2016.

HORTA, Reginaldo José. Por uma ética não especista: Peter Singer e a questão do estatuto moral dos animais não-humanos. Dissertação de mestrado. Faculdade Jesuíta de Filosofia e Teologia (FAJE), Belo Horizonte: 2015.

LINZEY, Andrew. Los animales en la teologia. Tradução de Ignacio Ribera Galán. Barcelona: Herder, 1996. Título original: Animal theology. $\overline{\text { Press, } 2000 .}$

. Animal Gospel. Louisville, Kentucky: Westminster John Knox

. Creatures of the same God: explorations in animal theology. New York: Lantern Books, 2009.

.Christianity and the rights of animals. Eugene: Wipf and Stock, 2016.

PALHANO, Jerson José Darif; SANCHES, Mario Antonio. Sobre os animais não humanos: um resgate teológico. Revista BioEthikos, São Paulo, v. 6, n. 3, p. 287-299, jul/set 2012.

. Teologia da compaixão com os animais: a prática de Jesus. Revista Pistis Praxis, Teol. Pastor., Curitiba, v. 5, n. 1, p. 169-184, jan./jun. 2013. PAPA FRANCISCO. Carta Encíclica Laudato Si' - Sobre o Cuidado da Casa Comum. São Paulo: Loyola, 2015.

SUSIN, Luiz Carlos; ZAMPIERI, Gilmar. A vida dos outros: ética e teologia da libertação animal. São Paulo: Paulinas, 2015.

ZAMPIERI, Gilmar. A Encíclica Laudato Si' e os animais. Cadernos Teologia Pública, ano XII, v. 13, n. 110, São Leopoldo: Universidade do Vale do Rio dos Sinos. 2016. 